\title{
Wage differentials after a career break: A latent growth model using Belgian register data
}

Dimitri Mortelmans University of Antwerp, Belgium
dimitri.mortelmans@uantwerpen.be
$\begin{aligned} & \text { Dorien Frans University of Antwerp, Belgium }\end{aligned}$

(Received June 2015 Revised July 2016)
http://dx.doi.org/10.14301/Ilcs.v8i2.359

\section{Abstract}

This article analyses income differentials after re-entry into the labour market between people who have had a career break and people who have not by applying latent growth modelling to a sample of longitudinal register data. The results suggest that when comparing the incomes of those who return from a break with those who did not have a break there are significant initial income differences to the disadvantage of the former. Moreover, the income differentials between men were greater than those between women. In addition, significant additional income growth was found after the break for women but not for men. The evidence suggests that such leave is more socially acceptable for women but leads to significant negative income differentials among men.

\section{Keywords}

Career break, economic consequences, wage differentials, latent growth modelling, register data

\section{Introduction}

In Belgium, the government-supported Career Break Scheme allows employees to interrupt their career temporarily while receiving a limited substitute income. The underlying idea was to create more space in the labour market for the unemployed. Over the years, the scheme gradually shifted from economic to more individual-oriented measures such as thematic leave (i.e. parental leave, leave for medical support or leave for palliative care). In the international literature, little is known about the consequences of these types of career break schemes. It is generally believed that employees who interrupt their careers will be penalised in the labour market. Some studies have shown the negative effects of taking a career break on career development in terms of fewer promotions and wage depreciation in comparison to individuals with continuous working patterns (e.g. Spivey, 2005). This article contributes to the literature by focusing on wage differentials after a career break. Using longitudinal register data, we will analyse wage differentials between those who took a break and a control group that did not interrupt their career during the same period.

\section{Background to the time credit scheme in Flanders \\ The Belgian Career Break Scheme was introduced in 1985 in response to the high unemployment rate, offering employees a limited substitute income during the period of work interruption. In 2002, the}


programme was modernised to become a general Time Credit Scheme in the private sector. The new scheme was promoted as a way to increase quality of life, with a specific emphasis on a work-life balance. The Time Credit Scheme enjoys great popularity and the number of people entering the system has increased rapidly over the years: from 156,584 in 2003 (3.4\% of the total labour force) to 276,301 in 2014 (5.5\% of the total labour force). The majority of people taking a career break (65\%) are located in the northern part of the country (the Dutch-speaking region of Flanders), where the regional government provides additional financial incentives to take a career break.

There are several options that people can choose from when taking a career break: full-time or parttime breaks, and specific thematic leave. A full-time career break allows employees to interrupt their careers and cease work activities completely for a limited period of time for whatever reason. In the private sector such a career break is called 'Time Credit'. The distinction between the private and public sectors and the accompanying name change was introduced in 2002 when the system of career breaks was restructured. However, apart from the name and extended duration in the public sector (six years rather than five), both systems are similar. In 2003, less than 8,500 people took a full-time career break. After the reforms, the number of full-time breaks remained rather low in both sectors and even diminished slightly over the years. In 2015, nearly half of the people (43.6\%) taking a full-time career break, whether in the public or the private sectors, were between 25 and 40 years old.

The second option is to take a partial career break. Each employee is free to choose the extent to which he or she wants to reduce their workload, whether by $50 \%, 33 \%, 25 \%$ or $20 \%$. We will not make a distinction between these categories in this article. A partial reduction in working hours is by far the most popular option across all types of career break. The popularity of the part-time scheme in the private sector has grown spectacularly since its introduction in 2002. A part-time career break is especially significant for people aged 50 years or older, as it gives them the opportunity to work part-time until their retirement. This partially explains why there is a low labour market participation rate for people over 50 in
Belgium. Almost $66 \%$ of those who took a part-time break in 2010, either in the public or private sectors, were 50 years or older.

The third option involves specific categories of career breaks that can be taken based on predefined conditions. Among these 'thematic' forms of leave are three important types: parental leave, leave for medical assistance or leave to undertake palliative care. Of these three possibilities, parental leave is by far the most popular (85\%), while leave for medical assistance accounts for less than $15 \%$ and leave for palliative care is very limited, at less than $1 \%$.

The majority of people who take a career break choose to do so on a part-time basis. In 2014, almost 64,000 people ( $1.3 \%$ of the total labour force) took a part-time career break, either in the private or the public sectors. There are also important differences between men and women in the take up rates. More than $66 \%$ of people taking a career break are women. This female majority becomes even more apparent among the full-time breaks and thematic leave $(77 \%$ and $72 \%$, respectively). However, this percentage is lower among the part-time breaks (63\%), where the part-time options are gradually becoming more attractive to men. This increase seems to be primarily due to the rise in part-time breaks among men who are 50 years or older.

Previous research has also shown that the intentions behind the use of a break are gender related. Desmet, Glorieux, and Vandeweyer (2007), for example, showed that the main motive for taking a break for women was childcare (especially those with young children), while for men, ending their career on a part-time basis was clearly the most dominant reason. Nevertheless, some men also use the scheme to try out a new job or to start their own business.

\section{Literature review: Consequences of} career breaks

A work-life balance is a priority in a series of EU policy initiatives on childcare, the amount of time people work and the need for flexible arrangements. The EU considers work-life balance policies to have a direct effect on labour participation and quality of life (Eurofound, 2004). Flexible arrangements such as the Career Break Scheme are considered useful 
instruments to achieve a better work-life balance (Hyman, 2005). Moreover, the involvement of fathers in childcare has been shown to increase when paternal leave is available (Bünning, 2015; Nepomnyaschy \& Waldfogel, 2007).

There are indications from previous research that there are potential unwanted negative consequences on subsequent wages due to career breaks (e.g. Arun, Arun, \& Borooah, 2004). A common element in all these studies is the focus on maternal and paternal leave. These studies looked at the influence of leaving the labour market after a first or subsequent birth and consistently showed that mothers experience a wage penalty (Gangl \& Ziefle, 2009; Waldfogel, 1998a, 1998b). While this wage gap is partly due to differences between the background characteristics of women, a considerable part can also be attributed to occupational segregation (Manning \& Petrongolo, 2008). For men, there is little research data on this topic. The dominant strand in recent literature looks at the effect of paternal quotas on subsequent earnings. Both in Scandinavia (Norway, Sweden) and in Germany, legislation encourages fathers to take parental leave after the birth of their first child (Geisler \& Kreyenfeld, 2011). The effects of uptake on earnings were found to be negative in Norway (Rege \& Solli, 2013) and negative but insignificant in Sweden (Ekberg, Eriksson, \& Friebel, 2013). For Germany, studies only looked at uptake but not wage consequences (Trappe, 2013). Thus, most studies point to clear income losses as a consequence of a career break. Immediately after a career interruption, wages will be relatively lower than before (Mincer \& Ofek, 1982).

The effect of career breaks also seems to be dependent on the timing and the length of the break. Corcoran and Duncan (1979), for example, found that there was only a negative effect on wages when the break occurred at the beginning of a career. They also found evidence of recovery from an initial income decrease after the break, as wages increased more rapidly subsequently (Corcoran, Duncan, \& Ponza, 1983). Other studies found that longer interruptions could lower wages. In addition, short interruptions had a rather small or no impact on further career development compared to longer interruptions (Mincer \& Ofek, 1982; Schönberg \& Ludsteck, 2007; Theunissen, Verbruggen, Forrier, \& Sels, 2009).
A career break leads to a significant wage loss during the break because the substitute income is much lower than the wage being paid. Moreover, a career break not only brings the accumulation of human capital to a halt during the break, but can also lead the existing human capital to deteriorate. This can have a negative effect on the productivity of such employees (Becker, 1985). According to human capital theory, wages and job opportunities reflect the productivity of individuals. This productivity increases as education, training and job experience increase (Becker, 1964). Therefore, it can be assumed that a career break interrupts the accumulation of work experience and can even lead human capital to deteriorate during the break. As a consequence, it can lead to a worker having a lower productivity and may reduce their career prospects. This may explain the relative lower wages paid to people on their return to work after a career break (Gangl \& Ziefle, 2009). Our first hypothesise, therefore, is that after a career break, we will find a lower income for those who took a break compared to those who worked without a break (H1).

The wage loss experienced immediately after the break is followed by a recovery period. This recovery period is a phase where previously eroded human capital might be restored (i.e. a catch-up effect). Given that such a process would be quicker and less costly than building up new human capital, this process and the wage growth will eventually slow down and continue to grow at the rate of a worker without a career break (Mincer \& Ofek, 1982). During this recovery period, we hypothesise that the wage growth of people who had taken a career break will be higher than those who did not take a break because there would be a catch-up effect in relation to work experience. In the long run, human capital theory expects wage losses to be compensated. Therefore, our second hypothesis is that the income growth rates will be significant and positive for people with a career break compared to people without a career break $(\mathrm{H} 2)$.

In some studies, the loss of human capital could not explain all of the wage differentials. The wage losses resulting from career breaks were found to exceed losses due to the work experience foregone (i.e. an indicator of human capital) (Beblo \& Wolf, 2002). Moreover, some studies found gender 
differences in the effects of career breaks on income that suggest other explanations are important because the loss in human capital can be assumed to be equal among men and women (Albrecht, Edin, Sundstrom, \& Vroman, 1999). These studies refer to signalling theory to explain these gender differences, which suggests that a temporary career break can send a signal to employers that such people are less committed to their job and prioritise their family over their work. This signal can play an important role in decisions regarding promotions where higher commitment is expected. People who interrupt their career are, in fact, stigmatised for doing so (Beblo \& Wolf, 2002). Men, in particular, are seen to be less committed to their jobs if they take a break. Employers suggest that they would respond with lower wages. Women, however, are traditionally seen as the ones to take a break for family reasons. As a consequence, they do not send the equivalent signals to their employers when taking a career break. The smaller wage loss found among women can thus be explained as a loss in human capital, while the wage loss for men is attributed more to the stigmatisation process (Albrecht et al., 1999).

Men having a career break may therefore be expected to be penalised more in the labour market than women, with the wage differentials between men with and without a break expected to be higher than the wage differentials between women with and without a break. Since a career break is generally used by women, it is suggested that this is already reflected in the lower wages of women compared to men (Gangl \& Ziefle, 2009). Men, however, are not expected to take a career break and would more likely be stigmatised for doing so. Therefore, our third hypothesis is that an interaction effect between gender and career break is significant, where the initial income differential after the break between men with or without a break is higher than the income differential between women with or without a break $(\mathrm{H} 3)$.

Since most of the research in this field concentrates on first births and maternity leave, little is known about potential age effects. When looking at the uptake of parental leave schemes, human capital is used to explain the uptake of leave by younger partners in a couple. This relative resources hypothesis states that the partner who has the least work experience will lose less by taking a break (Geisler \& Kreyenfeld, 2011). Since our study uses data across the life course, and births are not the prime focus, we need to take age into account. We do not follow the relative resources hypothesis in our study, as we consider workers in different age groups rather than age differences within a couple. Since older workers take leave as a pathway to retirement, we consider the age of 50 as a crucial turning point in a Belgian career. Although the retirement patterns of men and women are different (De Preter, Van Looy, \& Mortelmans, 2014), we can take the same age as a turning point for both men and women in the labour market. However, we do not consider the age effect to be independent of gender, with women taking leave more when they become a parent, and men considering the system to provide an end of career strategy. Therefore, our fourth hypothesis is that the interaction effect between gender and career break is age dependent, with the initial income differential after the break between younger men higher than the income differential between older men with or without a break $(\mathrm{H} 4)$.

In general, the empirical evidence is not unequivocal with regard to the financial consequences of career breaks. The actual effect of a career break on subsequent income remains unclear, neither do the results show a clear picture of the underlying processes determining income trajectories after a career break. There are possible selection effects. For example, employees who have taken a career break might have followed a similar development in their career path even if they had not taken this break; in other words, employees might have less upward career mobility regardless of a career break because they do not have the ambition or an interest in building a 'career'. People motivated to achieve the highest levels in their career will probably work full-time, work over-time and never interrupt their careers. Someone prioritising family life, however, is more likely to work fewer hours (part-time if possible), stay at home to look after a sick child and take up options such as a career break. As far as the data allows us, we will thus take the potential selection effects into account in our models (cf. Ekberg et al., 2013).

In summary, previous studies are often limited in scope. Almost all previous research relates to the 
gender gap in wage differentials and focuses primarily on the effects of parental leave for women (e.g. Beblo \& Wolf, 2002; Dex, 1999; Pylkkanen \& Smith, 2004). Few studies have examined the differences between men and women or taken a male perspective (e.g. Ekberg et al., 2013; Trappe, 2013). In this article, we want to go beyond these shortcomings by examining the impact of a career break on the income of both men and women across the life course. Additionally, we will use a large sample of reliable longitudinal data to estimate the effects, rather than survey measures of income.

\section{Data and methodology}

\section{Data}

Longitudinal data from a representative sample of workers taking a career break during the observation period was required to test these hypotheses. We obtained such a sample from the Datawarehouse Labour Market and Social Security of Belgium. This database combines data from various social security institutions in the country. The sample population consists of people living in Flanders who were active in the labour market in the year of sampling. The data at our disposal spans the period from the second quarter of 1998 to the fourth quarter of 2006. A great advantage of such register data is the accurate and complete income data. We can examine the income differentials after a break as well as the differentials in subsequent income growth. We also have information regarding the length and number of career breaks in this period, and the sample also provides enough statistical power for our models, whereas data on career breaks in general-purpose surveys would usually be numerically insufficient to test our hypotheses.

A total of 90,414 individuals were randomly selected, and the sample was drawn on a yearly basis. For 2000 to 2006, a $10 \%$ sample of all individuals taking a career break (in each of these seven years) was taken. In order to be able to compare the incomes and income growth, a 'control group' was created, with the same number of people working without having had a career break randomly selected each year (also totalling 90,414 individuals). This control group was sampled to match the career interrupters in terms of age and gender for every quarter in the first sample.

For the purposes of this article, we only used people taking one career break (leaving approximately $80 \%$ of the original sample: 69,023$)$. In order to model the influence of the income trajectory before and after the break, we limited the sample to breaks ending in 2003. This decision further limited the sample to 5,537 people. From the control sample (initially 67,906 individuals), we randomly selected a 2003 sample of 8,259 individuals, who were all working in that year. The selection of the 2003 subsample was done for several reasons. Firstly, the subsample allowed us to control for possible periodic effects. Because the individual cases are spread over the years, possible income differences could be due to the different times at which the breaks were observed. Secondly, the selection allowed us to examine part-time career breaks that extended for four or five years. We were also able to include the new career break scheme (from 2002), albeit for a short period of time (maximum one year).

\section{Measures}

Income is the dependent variable in the multilevel models presented below. We used the gross income measured on a quarterly basis. For each quarter, the incomes were adjusted for inflation, with 2004 as the base year. To linearise the individual income trajectories and to address the ways in which income data is commonly skewed, the natural logarithm of income was modelled in our analyses (In_inc). For the interpretation of the results, income was translated back into the original scale in euros (by taking the antilog).

Other variables available from the register data were the presence of children in the household (introduced as a time-varying dummy in the model), age (age ${ }^{2}$ was also included in the models) and a time-constant dummy indicating whether the individual was younger or older than 50 when taking the career break. For the control group, this dummy registers whether the person was younger or older than 50 in the first quarter of 2003.

\section{Analytic strategy}

The research questions were examined using multilevel models of change, also known as longitudinal growth models (Singer \& Willet, 2003). 
This is a better way to examine the data than traditional regression analyses because longitudinal data can be seen as multilevel data with repeated measures nested within individuals. This also allowed us to be more flexible in the assumptions imposed on the models. The classic assumptions in OLS regression analyses, i.e. independent and identically distributed residuals, and homoskedastic variance across occasions and individuals, are less credible in longitudinal data (Singer \& Willett, 2003).

Our model is essentially a multilevel model with two levels. On the first level, we located the repeated measurement of different variables within one person. As such, we postulated a level one model that represents the expected change in income level within one individual. This is also referred to as the individual income trajectory. On the second level, we located individual-specific variables to explain some of the variability in income trajectories between individuals.

We were interested in the change in income before, surrounding and after the career break. Because the Datawarehouse Labour Market and Social Security of Belgium data spans the period from the second quarter of 1998 to the fourth quarter of 2006, we were able to estimate the income trajectory over a 35-quarter time-span. This observational window is represented in figure 1 with the arrow labelled 'Quarter'. In the tables, we will refer to this general time trajectory as TIME1. 


\section{Figure 1}

Time Variables that constitute the Individual Income Trajectory (example with career break between quarter 1 and 5)

\begin{tabular}{|c|c|c|c|c|c|c|c|c|c|}
\hline & & & \multicolumn{3}{|c|}{ CAREER BREAK } & & & & \\
\hline 1 Quarter: General wage growth & 0 & 1 & 2 & 3 & 4 & 5 & 6 & 7 & 8 \\
\hline 2 Break: wage effect of taking the break & 0 & 0 & 1 & 1 & 1 & 1 & 1 & 1 & 1 \\
\hline 3 Return: wage effect of returning & 0 & 0 & 0 & 0 & 0 & 1 & 1 & 1 & 1 \\
\hline 4 Recovery: wage growth after the break & 0 & 0 & 0 & 0 & 0 & 0 & 1 & 2 & 3 \\
\hline 5 Selection effect: Had a break (1) & 1 & 1 & 1 & 1 & 1 & 1 & 1 & 1 & 1 \\
\hline
\end{tabular}


Due to the event of a career break, we expected a discontinuous income trajectory rather than a linear one, which was modelled using the following basic variables: 'Break' (TIME2), 'Return' (TIME3) and 'Recovery' (TIME4). This regression specification is in line with the work of Kletzer and Fairlie (2003) but adapted to this particular time trajectory (see also: Couch \& Placzek, 2010; Jansen, Mortelmans, \& Snoeckx, 2009). Figure 1 illustrates the parameterisation of time.

In the unconditional growth model - the model without any covariates except for those mentioned above - the intercept estimates In_inc at Time zero, the start of the observation window for all respondents irrespective of the event of a career break. As 'Quarter' is a continuous time variable, the estimate for the slope of the curve associated with the general growth indicates the linear trend in income during the administrative panel. 'Break' (TIME2) is essentially a time-varying dummy variable, which has the value zero for all employees not interrupting their career throughout the observation window. For the respondents with a career break, it changes to one in the quarter that the break was taken and continues to have the value one during the whole post-break period. The break effect thus assesses the impact of the career break based on the income level in the quarter the break was taken. For all those not taking a career break, it is assigned zero throughout the observation window.

'Return' (TIME3) is a comparable parameterisation for the quarter in which a career break is ended. It receives the value one in the quarter a career break ends and continues to have the value one until the end of the observation window. Again, noninterrupters have a zero-value during the whole panel. The slope associated with 'Recovery' (TIME4) assesses the linear growth in income trajectory in the post-break period. This variable is given the value one, one year after returning from a career break and increases from there on. We refer to this effect as the income growth after the break because the slope gives an insight into the deviation for individuals who took a break compared to the general income trajectory of all individuals. For example, a positive slope indicates a larger increase in income growth, compared to the general income growth throughout the sample.

\section{Table 1. Taxonomy of multilevel models for change}

Level 1/Level 2 specification

Level 1 model Level 2 model

Composite model

\begin{tabular}{|c|c|c|c|}
\hline Model 1 & $L n \_y_{i j}=\pi_{o i}+E_{i j}$ & $\pi_{\mathrm{oi}}=\gamma_{00}+\zeta_{\mathrm{oi}}$ & $L n_{-} \_y i j=Y_{00}+\left(\zeta_{o i}+E_{i j}\right)$ \\
\hline \multirow[t]{6}{*}{ Model 2} & $\operatorname{Ln} \_y_{i j}=\pi_{0 i}+\pi_{1 i} * T_{I M E} 1_{i j}+\pi_{2 i}$ & $\pi_{0 i}=\nu_{00}+\xi_{0 i j}$ & $\operatorname{Ln}_{-} y_{i j}=\gamma_{00}+\gamma_{10} * T_{I M E} 1_{i j}+\gamma_{20} * T I M E 2_{i j}$ \\
\hline & *TIME $2_{\mathrm{ij}}$ & $\pi_{1 \mathrm{i}}=\gamma_{10}+\xi_{1 \mathrm{ij}}$ & $+\gamma_{30} * \operatorname{TIME}_{i \mathrm{ij}}+\gamma_{40} * \operatorname{TIME}_{i \mathrm{ij}}+\gamma_{50} *$ SELECTION $_{\mathrm{ij}}$ \\
\hline & $+\pi_{3 i}{ }^{*} \operatorname{TIME3}_{\mathrm{ij}}+\pi_{4 \mathrm{i}}$ & $\pi_{2 i}=\gamma_{20}+\xi_{2 i j}$ & $+\left(\xi_{0 i j}+\xi_{1 i j}{ }^{*}\right.$ TIME1 $1_{i j}+\xi_{2 i j}{ }^{*}$ TIME2 $2_{i j}+\xi_{3 i j}{ }^{*} \operatorname{TIME3}_{i j}$ \\
\hline & ${ }^{*}$ TIME4 $_{\mathrm{ij}}$ & $\pi_{3 i}=\gamma_{30}+\xi_{3 i j}$ & $\left.+\xi_{4 i j} * T_{I M E 4_{i j}}+\xi_{5 i j} * S_{E L E C T I O N}+E_{i j}\right)$ \\
\hline & $\Pi_{5 i} *$ SELECTION $_{i j}+E_{i j}$ & $\pi_{4 i}=\gamma_{40}+\xi_{4 i j}$ & \\
\hline & & $\pi_{5 i}=\gamma_{50}+\xi_{5 i j}$ & \\
\hline
\end{tabular}

We also modelled the instantaneous impact of gender, age and other covariates on the income level in the quarters during and following the break, as well as the impact of these covariates on the deviation of the general linear growth rate. In order to achieve this, we added interaction terms between the explanatory variables and the break, return and recovery effect, respectively.

Finally, we also included a time-constant dummy variable indicating whether the respondent did take a career break in this sample. This strategy allowed us to account for possible differences between those 
who do and those who do not interrupt their career before the actual break is taken (this is called the selection effect in figure 1). Alternatively, selection effects could be ruled out using a fixed effects approach. Like the random effects model we propose here, fixed effects models deal with the problem of dependence. Such models focus on explaining the within-person variability only by controlling for all stable characteristics of respondents, observed or not. By adopting such an approach, we would, by definition, lose all time-constant explanatory variables. Looking for a balance between controlling for unobserved heterogeneity and insight into the processes at hand, we believe the multilevel model of change, corrected for selection, is a sound alternative to a fixed effect model.

\section{Findings}

\section{Sample characteristics}

The sample of people taking a career break was compared to the control group in 2003 with regard to certain characteristics (see table 2). We looked at both groups according to age and gender. Apart from the fact that there are more people in the control group $(8,259$ vs 5,537$)$, we can see that the distribution is comparable in both groups. In the career break group, data on age was missing in six cases. We can see from the table that most men are 50 years or older $(54.67 \%$ and $52.93 \%$, respectively) and there are slightly more women of 50 years or older in the career break group (23.97\%) compared to the control group (16.35\%). According to the household typology LIPRO, in 2003 (results not shown), we find that the career break group consists of slightly more married people than the control group, at $19.0 \%$ and $16.0 \%$, respectively. There are also slightly more married people with children among the career break group (53.3\%) compared to the control group (45.4\%). The control group, however, consists of more single people $(11.0 \%)$ than the career break group (6.9\%). The other categories are rather low in both groups.

Table 2. People with a career break and people without a career break across age and gender

With Career Break

Without Career Break

\begin{tabular}{ccccccccccccccc}
\hline & Men & $\%$ & Women & $\%$ & Total & $\%$ & Men & $\%$ & Women & $\%$ & Total & $\%$ \\
$<25$ & 66 & 4.75 & 336 & 8.10 & 402 & 7.26 & 146 & 5.64 & 505 & 8.91 & 654 & 7.88 \\
$25-49$ & 564 & 40.58 & 2817 & 67.93 & 3381 & 61.06 & 1073 & 41.43 & 4237 & 74.74 & 5310 & 64.29 \\
$>=50$ & 760 & 54.67 & 994 & 23.97 & 1754 & 31.68 & 1371 & 52.93 & 927 & 16.35 & 2298 & 27.82 \\
Total & 1390 & 100.00 & 4147 & 100.00 & 5537 & 100.00 & 2590 & 100.00 & 5669 & 100.00 & 8259 & 100.00 \\
\hline
\end{tabular}


In table 3, we can see how our sample of people taking a career break is divided across the age categories, and the type of career break taken by men and women. Most people taking a career break are female $(4,147$ or $74.9 \%)$. There are considerable differences across the type of career break. Most men take a part-time break, especially in the public sector. Moreover, the part-time breaks taken by men are primarily situated among those aged 50 years or older, while the full-time options are most likely to occur among the middle-aged category (25-49 years).
For men, thematic leave is also primarily taken by those who are middle-aged. Most women also take a part-time career break. While this type of break is also popular among women aged 50 or older, contrary to men, the majority of those taking a parttime break lie in the middle-aged category. Significantly fewer women opt for a full-time break, with the main full-time users being middle-aged. Thematic leave is also very popular among women, with $89.04 \%$ belonging to the middle-aged category. 
Table 3. Gender and age differences in each type of career break

\begin{tabular}{cccccccccccccccccccc} 
& & $\begin{array}{c}\text { Part-time } \\
\text { (public) }\end{array}$ & $\%$ & $\begin{array}{c}\text { Full-time } \\
\text { (public) }\end{array}$ & $\%$ & Thematical & $\%$ & $\begin{array}{c}\text { Part-time } \\
\text { (private) }\end{array}$ & $\begin{array}{c}\text { Full-time } \\
\text { (private) }\end{array}$ & $\begin{array}{c}\text { Total } \\
\%\end{array}$ \\
\hline \multirow{2}{*}{ Men } & $<25$ & 22 & 3.99 & 8 & 6.06 & 5 & 2.36 & 13 & 4.5 & 18 & 8.78 & 66 & 4.75 \\
& $25-49$ & 94 & 17.03 & 74 & 56.06 & 191 & 90.09 & 73 & 25.26 & 132 & 64.39 & 564 & 40.58 \\
& $>=50$ & 436 & 78.98 & 50 & 37.88 & 16 & 7.55 & 203 & 70.24 & 55 & 26.83 & 760 & 54.68 \\
& Total & 552 & 100.00 & 132 & 100.00 & 212 & 100.00 & 289 & 100.00 & 205 & 100.00 & 1390 & 100.00 \\
\multirow{2}{*}{ Women } & $<25$ & 172 & 8.35 & 28 & 6.50 & 94 & 7.92 & 20 & 8.70 & 22 & 9.17 & 336 & 8.10 \\
& $25-49$ & 1145 & 55.58 & 291 & 67.52 & 1056 & 89.04 & 132 & 57.39 & 193 & 80.42 & 2817 & 67.93 \\
& $>=50$ & 743 & 36.07 & 112 & 25.98 & 36 & 3.04 & 78 & 33.91 & 25 & 10.41 & 994 & 23.97 \\
& Total & 2060 & 100.00 & 431 & 100.00 & 1186 & 100.00 & 230 & 100.00 & 240 & 100.00 & 4147 & 100.00 \\
\hline
\end{tabular}


These findings are in accordance with the descriptive statistics presented above. It seems that the public sector is overrepresented among those taking a career break, and particularly among individuals using the part-time option. From our analysis in the previous section, we saw that this ratio (public/private) changes throughout the years, where part-time breaks in the private sector become more important than the public sector and that thematic leave also becomes more popular among men.

\section{The unconditional means model}

In the analyses, we will begin by fitting two simple models: the unconditional means model and the unconditional growth model. These unconditional models partition and quantify the outcome variation in two important ways: the first model describes the amount of variance on each level across people regardless of time, and the second model does so across both people and time by including time as a predictor, allowing us to examine income growth at re-entry to the labour market after a break. These models allow us to determine whether there is any systematic variation in outcome which is worth exploring and where the variation is located (between or within people) (Singer \& Willett, 2003). Both models also provide baselines for subsequent comparisons of other models to which we add substantive predictors, such as career break type and gender, on the second level to explain the variance between individuals.

The unconditional means model (model 1 in table 4) does not describe change in the outcome over time. There are no predictors included in this model. In this null model, only variations in intercept are allowed. The income trajectory (In_inc or $\ln \_y_{i j}$ ) of a certain individual is flat since there are no slopes. This model only gives time-constant averages. The average of $\ln \_y_{i j}$ for individual $i$ is $\pi_{o i}$. The average of In_ $y_{i j}$ for all individuals is $Y_{o o}$. $E_{i j}$ is the variance on level one, which is the spread around the personspecific In_inc level over the quarters. $\zeta_{\text {oi }}$ is the variability of the average of In_inc between persons on level two that can possibly be explained by introducing covariates on this level.

In the null model, the average $\ln \_y_{i j}$ is 8,356 throughout the observational time for both the control group and the group of people who took a career break. The average income is $€ 4,256$ $\left(\mathrm{e}^{8,356}\right)$ /quarter or $€ 1,419 /$ month during the whole time period. At time $j$, In_ $y_{i j}$ varies from the average of individual $\mathrm{i}\left(\pi_{\mathrm{oi}}\right)$ by $\mathrm{E}_{\mathrm{ij}}$. All parameters are statistically significant. We therefore reject the null hypothesis for each group $(p<0.001)$ that the average income of people between 1998 and 2006 is zero.

A null model is always estimated first because it describes and partitions the outcome variation. The residual on level one represents the within person $\left(\sigma_{\mathrm{E}}^{2}\right)$ variation and the residual on level 2 represents the between person $\left(\sigma_{0}{ }^{2}\right)$ variation. Both variance components were significantly different from zero $\left(\sigma_{\mathrm{E}}{ }^{2}: 0.317\right.$ and $\sigma_{\mathrm{o}}{ }^{2}: 0.546$ with $\left.\mathrm{p}<0.01\right)$. To look at the amount of variation on each level, we looked at the intraclass correlation coefficient (ICC) from the unconditional model.

Intraclass correlation coefficient (ICC) $=\rho=$ $\sigma_{\mathrm{o}}{ }^{2} /\left(\sigma_{\mathrm{o}}{ }^{2}+\sigma_{\mathrm{E}}{ }^{2}\right)=0.63$

Of the variation in income (In_inc), $63 \%$ is due to variation between individuals and $37 \%$ to variation within individuals over time. In the observed quarters from 1998 to 2006, we can say that $37 \%$ of the variation in income can be ascribed to variation of income within the trajectory of each individual, or how each person's income changes over time, while $63 \%$ of the variation of income is due to variation between individuals, or how these changes differ across people.

\section{The unconditional growth model}

The unconditional growth model only has time as a predictor, with no other covariates taken into account (results not shown). This model fits the data better than the previous model, as both variance components declined in value. Because people can have different initial incomes as well as different income growths, we included the selection effect and the four time effects, both fixed and at random in the model (model 2). This did not considerably alter the estimates, but fit the data significantly better (lower $\mathrm{Chi}^{2} /$ deviance, $\mathrm{AIC}$ and $\mathrm{BIC}$ ). The variance components of the intercept, as well as the selection 
effect and the time variables, differed significantly from zero. The level two residual variances $\sigma_{0}{ }^{2}$ and $\sigma_{1}{ }^{2}$ now summarise between-person variability in initial status and rates of change. A significant intercept variance implies that the individuals have different initial status/values $\left(\sigma_{\mathrm{E}}^{2}: 0.177\right.$ with $\left.p<0.001\right)$.

Different variations of time indicate a significant variation between individuals in general income growth (TIME1), income drop (TIME2), income return (TIME3) or income recovery (TIME4). The overall intercept remains more or less the same $(€ 8,716$ or $€ 2,033 /$ month). The first TIME variable shows the overall income growth in our time window. In general, individual incomes rise by 0.005 per quarter. This is equivalent to $€ 10\left(\mathrm{e}^{(8.716+0.005)}\right)$ /quarter or $€ 41 /$ year. TIME2 models the income drop at the start of the break. This effect is negative and shows a significant instant drop in income of $€ 1,353$ ( $\mathrm{e}^{(8.716+-}$ $0.407) / 4) /$ month. The effect of returning to the previous job (TIME3) shows a non-significant positive effect of
0.004 or $€ 2,041\left(e^{(8.716+0.004)}\right)$. The income effect of returning after a break is a little smaller than the income drop at the start of the break. After the return, we see no significant difference in income growth between those who took a break and the control group. The effect of TIME4 is positive and shows a steady recovery of income after the initial return effect.

The selection shows the income level of those individuals who will take a break in the observation window, compared to the control group. The effect is negative and significant. This implies that those who decide to take a break are already earning less than the individuals in the control group. The difference amounts to $€ 443 /$ month $\left(\mathrm{e}^{(8.716-0.246)} / 4\right)$.

Using the models below, we will try to explain the income differences before, during and after the break by including covariates on the second level and bringing them into interaction with our time variables. 
Table 4. Multilevel models for wage differentials after a career break $(n=13802)$

\begin{tabular}{|c|c|c|c|c|c|c|}
\hline & & Model 1 & Model 2 & Model 3 & Model 4 & Model 5 \\
\hline \multicolumn{7}{|l|}{ FIXED EFFECTS } \\
\hline \multirow[t]{6}{*}{ Initial status } & Intercept & $8.356 * * *$ & $8.716 * * *$ & $8.521 * * *$ & $8.528 * * *$ & $8.773 * * *$ \\
\hline & Men & & & $0.627 * * *$ & $0.604 * * *$ & $0.513 * * *$ \\
\hline & Age & & & & & $-0.001 * * *$ \\
\hline & $\mathrm{Age}^{2}$ & & & & & $0.000 * * *$ \\
\hline & $\begin{array}{l}\text { Younger than } 50 \\
\text { (dummy) }\end{array}$ & & & & & $-0.269 * * *$ \\
\hline & Has children & & & & & $-0.036 \mathrm{~ns}$ \\
\hline \multirow[t]{2}{*}{ 1. General income growth } & Intercept (TIME 1) & & $0.005 * * *$ & $0.005 * * *$ & $0.005 * * *$ & $0.006 * * *$ \\
\hline & Time $1 *$ Men & & & & $-0.004 * * *$ & $-0.004 * * *$ \\
\hline \multirow[t]{2}{*}{ 2. Break } & Intercept (TIME 2) & & $-0.407 * * *$ & $-0.399 * * *$ & $-0.408 * * *$ & $-0.4144 * * *$ \\
\hline & Time $2 *$ Men & & & & $0.029 \mathrm{~ns}$ & $-0.032 \mathrm{~ns}$ \\
\hline \multirow[t]{2}{*}{ 3. Return } & Intercept (TIME 3) & & $0.004 \mathrm{~ns}$ & $0.010 \mathrm{~ns}$ & $0.059 * * *$ & $0.060 * * *$ \\
\hline & Time $3 *$ Men & & & & $-0.187 * * *$ & $-0.188 * * *$ \\
\hline \multirow[t]{2}{*}{ 4. Recovery } & Intercept (TIME 4) & & $0.004 * * *$ & $0.004 * * *$ & $0.008 * * *$ & $0.008 * * *$ \\
\hline & Time $4 *$ Men & & & & $-0.018 * * *$ & $-0.018 * * *$ \\
\hline \multirow[t]{4}{*}{ 5. Selection } & Break (ref. = no break) & & $-0.246 * * *$ & $-0.159 * * *$ & $-0.165 * * *$ & $-0.127 * * *$ \\
\hline & Break * Men & & & $-0.218 * * *$ & $-0.200 * * *$ & $-0.219 * * *$ \\
\hline & Break * Younger than 50 & & & & & $-0.068 \mathrm{~ns}$ \\
\hline & Break * Has children & & & & & $-0.014 \mathrm{~ns}$ \\
\hline
\end{tabular}




\title{
VARIANCE COMPONENTS
}

Level 1 Within-person

In general income level

$0.317 * * *$

$0.177^{* * *}$

$0.177^{* * *}$

$0.177^{* * *}$

$0.177^{* * *}$

Level 2 Between-persons

\author{
In general income level \\ In general growth (time \\ 1) \\ In break effect (time 2) \\ In return effect (time 3 ) \\ In post-break growth \\ (time 4)
}

$0.546 * * *$

$0.466 * * *$

$0.417^{* * *}$

$0.417^{* * *}$

$0.396 * * *$

$0.000 * * *$

$0.000 * * *$

$0.000 * * *$

$0.000 * * *$

$\begin{array}{ll}0.326 * * * & 0.317 * * * \\ 0.387^{* * *} & 0.385 * * * \\ 0.004 * * * & 0.004 * * *\end{array}$

$0.317^{* * *}$

$0.320 * * *$

$0.004 * * *$

$0.378 * * *$

$0.374 * * *$

$004 * * *$

$0.004 * * *$

$0.004 * * *$

Fit

$-2 \mathrm{LL}$

Chi²-diff test

AIC

$\mathrm{BIC}$

$\begin{array}{lllll}785699.6 & 603688.8 & 602614.7 & 602435.9 & 600277.8 \\ & * * * & * * * & * * * & * * * \\ 785703.6 & 603700.8 & 602626.7 & 602447.9 & 600289.8 \\ 785718.6 & 603746.8 & 602671.9 & 602493.1 & 600335.0\end{array}$

Source: sample of administrative data (KSZ) in Flanders

$* * *$ p-level $<0.001 * *$ p-level $<0.01 *$ p-level $<0.05$ ns=not significant 


\section{Growth models with covariates}

In models 3 and 4, we included gender as a predictor of income. Since career breaks are gendered to a high degree, we wanted to measure the impact of career breaks on incomes and income growth for both men and women. In model 3, we only included gender to explain the general income differences and the selection effect. The positive main effect shows that, on average, men in our sample earn $€ 1,459 /$ month more than women $\left(\mathrm{e}^{(8.521+0.627)}\right)$. The negative selection effect from model 2 decreases slightly, but model 3 shows that men who take a career break earn less at the start of our observation window than women. In model 3, the estimated initial income in 1998 for people without a career break is $€ 1,673 /$ month $\left(e^{8,521} / 3\right)$. The estimated difference in income in 1998 between men and women with a career break is $€ 280 /$ month $\left(e^{8,716-}\right.$ $0.159 / 3-e^{8,521-0.159-0.218} / 3$ ). Model 3 is significantly better than model 2 because the deviance is significantly lower in the latter (a deviance of 1,074 for a difference of 2 degrees of freedom in a Chisquare distribution is significant at a $99.9 \%$ probability level). This was confirmed by the lower AIC and BIC for model 3 compared to model 2. This suggests that adding gender significantly improves the model.

Model 4 further extended the gender analysis by including interaction effects with the time variables. As such, we can explore the income changes experienced by men and women during and after a career break.

The main effects of the time variables and the selection effect do not change in terms of significance or direction. Only the main effect of gender decreases from 0.627 to 0.604 , still showing a higher general level of income for men. The interaction terms of gender with time are significant for TIME1, TIME3 and TIME4. The effect of TIME1 shows that the general income growth for men is smaller than that of women, which came as a surprise. The drop in income for those men who took a career break is non-significant. This implies that men drop about an equal amount of income as women. The recovery effect is negative for men, indicating that their income increases less sharply after returning to work. Again, this is surprising, but as we will show in model 5 , this is related to the omission of some important control variables. Finally, we can see that the interaction effect of MEN*TIME4 is significant. Just like the lower return rate, the recovery rate of men is also lower after taking a career break.

Because the Belgian labour market shows a high take up of career breaks by individuals at the end of their career, we decided to include a dummy variable that captured the fact that the person concerned is aged 50 or older. Together with some general control variables such as age, age ${ }^{2}$ and the presence of children, model 5 estimated the effect of this dummy on the income trajectory. Because of the complexity of the model, we only included the age-dummy and the presence of children as a main effect and as an interaction effect with our selection effect. The main effects were all in the expected direction. Individuals younger than 50 have lower incomes $(-0.269)$ and we see no effect of the presence of children on the general income level. There is also no selection effect of parents taking a career break on the income level $(-0.014)$ nor from the age dummy.

The important influence of gender and the symbolic age of 50 years have led us to examine their interrelation more closely. In table 5, we stratify our analyses in two directions. Firstly, we undertook separate gender analyses in order to see the genderspecific effect of the age boundary between men and between women. Secondly, we did the opposite by focusing on gender within groups younger and older than 50.

\section{Growth models for gender and age separately}

In model 6, we analysed the income differentials among the different types of career breaks for men and women separately. The overall effects remained more or less the same. The trajectory of incomes over time follows the same effect directions, with only minor differences in effect sizes between men and women. One clear difference was found in the selection effect. Men who interrupt their career have a lower income compared to men who continue working. The effect for women is also negative but to a far lesser degree. A second gender difference concerns the presence of children. For men, there is an overall positive effect on their income once a father, while women with children earn less than women without children. 
Table 5. Multilevel models for wage differentials after a career break $(n=13802)$

Model 6

Men
Model 7

Minus 50

yrs
50 and

older

FIXED EFFECTS

\begin{tabular}{|c|c|c|c|c|c|}
\hline \multirow[t]{6}{*}{ Initial status } & Intercept & $9.206 * * *$ & $8.819 * * *$ & $8.513 * * *$ & $8.771 * * *$ \\
\hline & Men & & & $0.554 * * *$ & $0.455 * * *$ \\
\hline & $\begin{array}{l}\text { Younger than } 50 \\
\text { (dummy) }\end{array}$ & $-0.222 * * *$ & $-0.281 * * *$ & & \\
\hline & Age & $-0.001 * *$ & $0.000 \mathrm{~ns}$ & $0.001 * * *$ & $0.001 \mathrm{~ns}$ \\
\hline & $\mathrm{Age}^{2}$ & $0.000 \mathrm{~ns}$ & $0.000 * * *$ & $0.000 * * *$ & $-0.000 \mathrm{~ns}$ \\
\hline & Has children & $0.096 * *$ & $-0.093 * * *$ & $-0.054 *$ & $-0.053 \mathrm{~ns}$ \\
\hline \multirow[t]{3}{*}{$\begin{array}{l}\text { 1. General income } \\
\text { growth }\end{array}$} & Intercept (TIME 1) & $0.003 * * *$ & $-0.003 * * *$ & $0.008 * * *$ & $\begin{array}{l}-0.003 \\
* * *\end{array}$ \\
\hline & Men & & & $-0.001 \mathrm{~ns}$ & $-0.000 \mathrm{~ns}$ \\
\hline & $\begin{array}{l}\text { Younger than } 50 \\
\text { (dummy) }\end{array}$ & $0.010 * * *$ & $-0.011 * * *$ & & \\
\hline \multirow[t]{3}{*}{ 2. Break } & Intercept (TIME 2) & $-0.351 * * *$ & $-0.427 * * *$ & $-0.418 * * *$ & $\begin{array}{l}-0.424 \\
* * *\end{array}$ \\
\hline & Men & & & -0.009 ns & $-0.072 * *$ \\
\hline & $\begin{array}{l}\text { Younger than } 50 \\
\text { (dummy) }\end{array}$ & $-0.081 \mathrm{~ns}$ & $-0.010 \mathrm{~ns}$ & & \\
\hline \multirow[t]{3}{*}{ 3. Return } & Intercept (TIME 3) & $-0.206 * * *$ & $-0.114 * * *$ & $0.121 * * *$ & $\begin{array}{l}-0.113 \\
* * *\end{array}$ \\
\hline & Men & & & $-0.136 * * *$ & $-0.093 * *$ \\
\hline & $\begin{array}{l}\text { Younger than } 50 \\
\text { (dummy) }\end{array}$ & $0.195 * * *$ & $0.236 * * *$ & & \\
\hline \multirow[t]{3}{*}{ 4. Recovery } & Intercept (TIME 4) & -0.014 ns & $0.005 *$ & $0.0125 * * *$ & $0.005 * *$ \\
\hline & Men & & & $-0.017 * * *$ & $\begin{array}{l}-0.008 \\
* * *\end{array}$ \\
\hline & $\begin{array}{l}\text { Younger than } 50 \\
\text { (dummy) }\end{array}$ & $0.009 * *$ & $0.0177 * * *$ & & \\
\hline \multirow[t]{3}{*}{ 5. Selection } & $\begin{array}{l}\text { Break (ref. = no } \\
\text { break) }\end{array}$ & $-0.314 * * *$ & $-0.126 * *$ & $-0194 * * *$ & $-0.099 *$ \\
\hline & Break * Men & & & $-0.211 * * *$ & $\begin{array}{l}-0.245 \\
* * *\end{array}$ \\
\hline & Break* Younger & $-0.087 \mathrm{~ns}$ & $-0.079 \mathrm{~ns}$ & & \\
\hline
\end{tabular}


than 50

Break * Has

children

$\begin{array}{llll}-0.512 n s & 0.001 n s & 0.024 n s & -0.007 n s\end{array}$

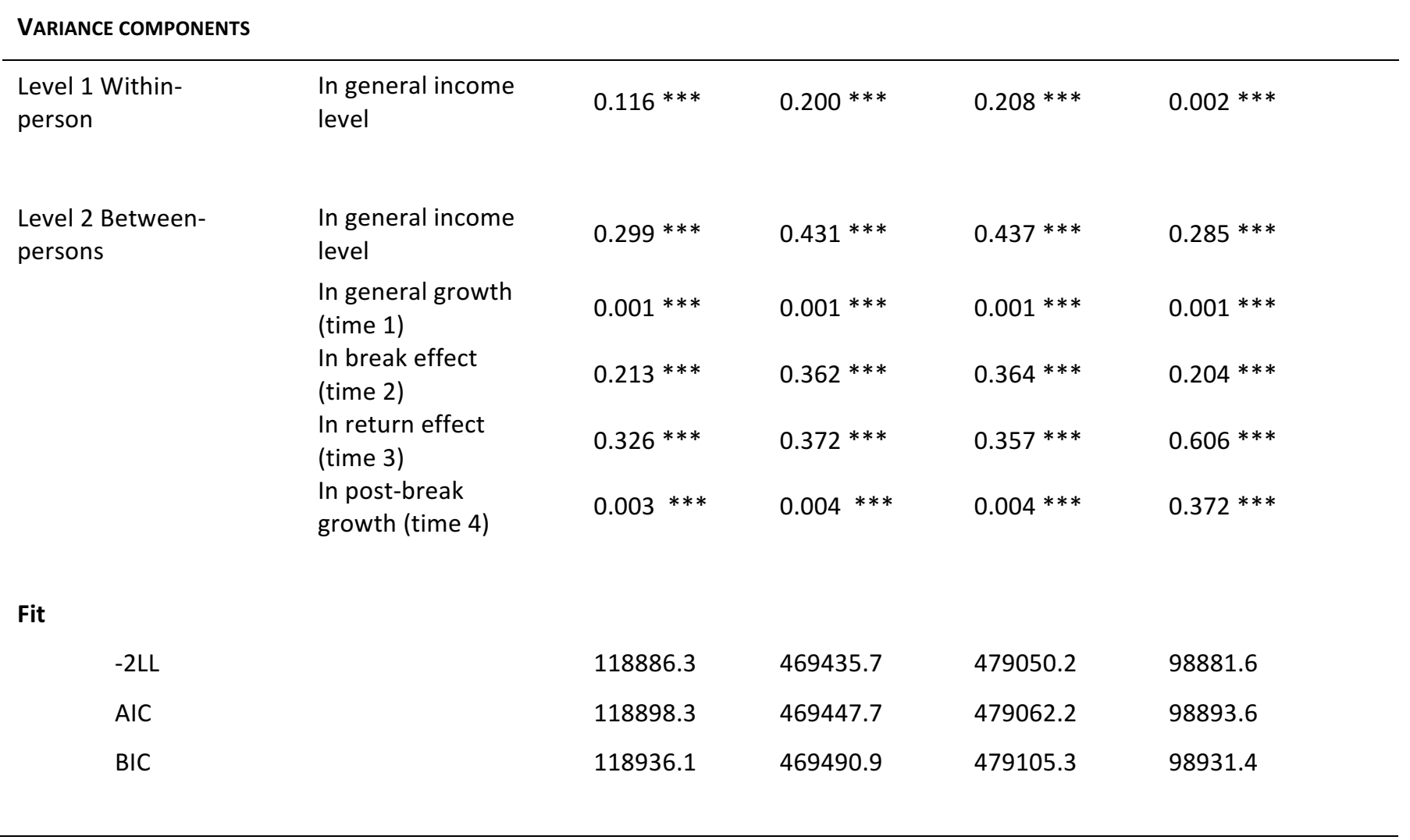


Splitting our analyses according to the age-50 dummy (Model 7) did not reveal any differences in the overall effects and the main growth trajectory. Employees above and below 50 have a positive growth curve with a decline in income for those taking a career break. This effect is only significant for those aged 50 and older. A major difference, however, is apparent in the return effect (TIME3). While individuals below 50 follow the general path of increasing their income after they return to work (0.121), older employees do not experience an increase but a further decrease their income when returning. We assume that these older workers reduce their working hours after their break and therefore show no gain after returning to the workplace. A second result in which the age divide clearly plays a role can be found in the selection effect. The overall selection effect for employees below 50 is significant and negative, indicating that those with a lower income take career breaks more often. Above 50, this selection effect is only significant to the 0.05 level.

\section{Discussion and conclusion}

When looking at income trajectories before and after a career break, we observed a clear effect of the break, resulting in a relatively lower income after the break compared to the situation before $(\mathrm{H} 1)$. As human capital theory predicted, we saw a significant recovery effect in the years after the break $(\mathrm{H} 2)$. There is a catch-up effect in relation to work experience and slowly the gap closes between the incomes of those who took a career break and their colleagues who did not.

The income differentials are much higher between men with and without a break than between women with and without a break. This is partly due to the initial income gap between men and women. Women lose less when taking a career break because their income is lower to begin with. However, when we controlled for the presence of children, we found that while women with a break showed significantly larger income growth after the break than women without a break, there were no significant differences in income growth between men, whether they took a break or not. In terms of income, men seem to be 'penalised' more for taking a career break than are women (H3).
This could be due to the fact that men are stigmatised more for taking a break. As it is not common for men to do so, this may send a signal that they are less committed to their job, which then leads to lower wages (signalling theory).

According to statistical discrimination theory, the lower wage loss found for women could also be due to the fact that women are penalised by lower wages regardless of a career break because it is already anticipated that they will take a break. By controlling for a selection effect, this turned out to be the case, but even more so for men taking a break than for women. Men on lower incomes tend to take a career break more often than women on lower incomes. We observed a reversed 'double standard' working against men (Foschi, 2000). Evaluations and expectations differ for men and for women and taking a career break might be subject to different evaluative processes within the labour market. Although we do not possess data showing the influence of these implicit standards, research has already shown the presence of gendered evaluative processes (Beblo \& Wolf, 2002; Foschi, 1996).

Women taking a career break had a significantly lower income than women without a break, after controlling for age and child-related covariates. The fact that the child-related variables did not have a significant effect on the income differentials of men was remarkable, which might suggest that men take career breaks for personal or work-related reasons. For women, we saw a reverse selection effect for mothers. Mothers tend to have a higher income before they take a break. We do not have data on educational levels in the Datawarehouse but we assume that this effect could be due to an educational gradient in the taking of career breaks among women.

Because the analysis concerns Belgian data, special attention was paid to the age limit of 50 years. Beyond this age, employees can take career breaks in a system that allows them to ease out of the labour force as they approach retirement. The use of this system is partly responsible for the low labour market participation of those over 50 in Belgium.

The interaction model indeed showed that the income trajectories, especially for men, are different for younger employees. After 50, the selection effect of taking a career break disappears, indicating that all 
men over 50 use the system in order to reduce their working hours at the end of their career. Below 50, less well paid men take career breaks. The gendered consequences are also more men-friendly after 50 . While we still found negative consequences for men (and women) after 50, they were much more modest. Men who take a career break before 50 are particularly liable to experiencing negative consequences in terms of income trajectory, both during and after a career break ( $\mathrm{H} 4)$. Taking the specific Belgian context into account, it can be concluded that the results concerning employees over 50 were influenced more by the Belgian end-ofcareer measures when compared to other countries. These measures are unique to the country, such that we doubt the generalisability of the longitudinal income trajectories for people over 50 . For the major part of the sample, the results were not different from those studies of other career break systems. This implies that the gendered outcome of taking a career break reveals the negative outcomes in terms of income for men compared to women.

Despite the huge dataset and the reliability of the income data, this study has several limitations that need to be taken into account. A first limitation concerns the income data used in this study. The registers provided us with quarterly income data, and while this income is a reflection of the hourly wage of the individuals in the sample, the aggregated data does not allow us to convert the income back into hourly data.

As a result, we could not account for actual changes in work hours in our models. The changes in income are a proxy for changes in work hours, as Belgian legislation requires employers to allow employees to return with their original contracts. Income trajectories therefore reflect changes in hours worked or changes in the workplace (which is also limited in the rigid Belgian work force) (Kovalenko \& Mortelmans, 2014), although the models cannot account for the actual hourly wages behind the income trajectories.

A second limitation of the study was the absence of data on educational level. The registers do not include this characteristic of the individuals in question. Data on other more subjective work-related issues, such as career aspirations, were also not available. As a consequence, these kinds of analyses do have great statistical power but remain rather descriptive. Finally, a third limitation is related to this and concerns the possible presence of selection effects. It might be the case that specific groups of employees select themselves in the career break scheme. They could be individuals with a lower labour market commitment and less ambition for promotion. It might be the case that these personal characteristics are only partly represented by these workers' wages. We did include a selection effect in the models as a way to control for lower wages before the break, but this might not be the complete story. The income differences found were, nevertheless, significantly large, especially for men. Future research on the dynamics of these processes is required.

\section{References}

Albrecht, J. W., Edin, P. A., Sundstrom, M., \& Vroman, S. B. (1999). Career interruptions and subsequent earnings: A reexamination using Swedish data. Journal of Human Resources, 34(2), 294-311. https://doi.org/10.2307/146347

Arun, S. V., Arun, T. G., \& Borooah, V. K. (2004). The effect of career breaks on the working lives of women. Feminist Economics, 10(1), 65-84. https://doi.org/10.1080/1354570042000198236

Beblo, M., \& Wolf, E. (2002). Wage penalties for career interruptions: an empirical analysis for West Germany. Retrieved from

Becker, G. S. (1964). Human Capital: A theoretical and Empirical Analysis, with Special Reference to Education. New York: Columbia University Press. https://doi.org/10.1086/298075 
Becker, G. S. (1985). Human Capital, Effort, and the Sexual Division of Labor. Journal of Labor Economics, 3(1), S33-S58. https://doi.org/10.1086/298075

Bünning, M. (2015). What Happens after the 'Daddy Months'? Fathers' Involvement in Paid Work, Childcare, and Housework after Taking Parental Leave in Germany. European Sociological Review, 31(6), 738-748. https://doi.org/10.1093/esr/jcv072

Corcoran, M., \& Duncan, G. J. (1979). Work history, labor force attachment, and earnings differences between the races and sexes. Journal of Human Resources, 14(1), 3-20. https://doi.org/10.2307/145535

Corcoran, M., Duncan, G. J., \& Ponza, M. (1983). A longitudinal analysis of white women's wages. Journal of Human Resources, 18(4), 497-520. https://doi.org/10.2307/145441

Couch, K. A., \& Placzek, D. W. (2010). Earnings Losses of Displaced Workers Revisited. American Economic Review, 100(1), 572-589. https://doi.org/10.1257/aer.100.1.572

De Preter, H., Van Looy, D., \& Mortelmans, D. (2014). Retirement Timing of Dual-Earner Couples in 11 European Countries? A Comparison of Cox and Shared Frailty Models. Journal of family and economic issues, 36(3), 396-407. https://doi.org/10.1007/s10834-014-9403-6

Desmet, B., Glorieux, I., \& Vandeweyer, J. (2007). Wie zijn de loopbaanonderbrekers? Socio-demografische kenmerken, motivaties en arbeidshouding van loopbaanonderbrekers. Brussel: VUB.

Dex, S. (1999). Careers and motherhood: policies for compatibility. Cambridge Journal of Economics, 23(5), 641659. https://doi.org/10.1093/cje/23.5.641

Ekberg, J., Eriksson, R., \& Friebel, G. (2013). Parental leave - A policy evaluation of the Swedish "Daddy-Month" reform. Journal of Public Economics, 97, 131-143. https://doi.org/10.1016/j.jpubeco.2012.09.001

Eurofound. (2004). Living to work - working to live: Tomorrow's work-life balance in Europe (Vol. 8). Brussels: European Foundation for the Improvement of Living and Working Conditions,.

Foschi, M. (1996). Double standards in the evaluation of men and women. Social Psychology Quarterly, 59(3), 237-254. https://doi.org/10.2307/2787021

Foschi, M. (2000). Double standards for competence: Theory and research. Annual Review of Sociology, 26, 2142. https://doi.org/10.1146/annurev.soc.26.1.21

Gangl, M., \& Ziefle, A. (2009). Motherhood, labor force behavior, and women's careers: an empirical assessment of the wage penalty for motherhood in Britain, Germany, and the United States. Demography, 46(2), 341369. https://doi.org/10.1353/dem.0.0056

Geisler, E., \& Kreyenfeld, M. (2011). Against all odds: Fathers' use of parental leave in Germany. Journal of European Social Policy, 21(1), 88-99. https://doi.org/10.1177/0958928710385732

Hyman, J. (2005). Getting on or getting by?: Employee flexibility and coping strategies for home and work. Work, Employment \& Society, 19(4), 705-725. https://doi.org/10.1177/0950017005058055

Jansen, M., Mortelmans, D., \& Snoeckx, L. (2009). Repartnering and (Re)employment: Strategies to Cope With the Economic Consequences of Partnership Dissolution. Journal of Marriage and Family, 71(5), 1271-1293. https://doi.org/10.1111/j.1741-3737.2009.00668.x

Kletzer, L. G., \& Fairlie, R. W. (2003). The long-term costs of job displacement for young adult workers. Industrial \& labor relations review, 56(4), 682-698. https://doi.org/10.1177/001979390305600408

Kovalenko, M., \& Mortelmans, D. (2014). Does career type matter? Outcomes in traditional and transitional career patterns. Journal of vocational behavior, 85(2), 238-249. https://doi.org/10.1016/j.jvb.2014.07.003

Manning, A., \& Petrongolo, B. (2008). The Part-Time Pay Penalty for Women in Britain*. The Economic Journal, 118(526), F28-F51. https://doi.org/10.1111/j.1468-0297.2007.02115.x

Mincer, J., \& Ofek, H. (1982). Interrupted Work Careers - Depreciation and Restoration of Human-Capital. Journal of Human Resources, 17(1), 3-24. https://doi.org/10.2307/145520

Nepomnyaschy, L., \& Waldfogel, J. (2007). Paternity Leave and Fathers' Involvement with Their Young Children. Community, Work \& Family, 10(4), 427-453. https://doi.org/10.1080/13668800701575077

Pylkkanen, E., \& Smith, N. (2004). The impact of family-friendly policies in Denmark and Sweden on mothers' career interruptions due to childbirth. IZA Discussion Paper, 1050, 1-36. 
Rege, M., \& Solli, I. F. (2013). The impact of paternity leave on fathers' future earnings. Demography, 50(6), 2255-2277. https://doi.org/10.1007/s13524-013-0233-1

Schönberg, U., \& Ludsteck, J. (2007). Maternity leave legislation, female labor supply, and the family wage gap. IZA Discussion Papers, 2699, 1-64.

Singer, J., \& Willett, J. (2003). Applied longitudinal data analysis. Modeling change and event occurence. New York: Oxford University Press. https://doi.org/10.1093/acprof:oso/9780195152968.001.0001

Spivey, C. (2005). Time off at what price ? The effects of career interruptions on earnings. Industrial \& labor relations review, 59(1), 119-140. https://doi.org/10.1177/001979390505900107

Theunissen, G., Verbruggen, M., Forrier, A., \& Sels, L. (2009). Career Sidestep, Wage Setback? The Impact of Different Types of Employment Interruptions on Wages. Gender, Work \& Organization. https://doi.org/10.1111/j.1468-0432.2009.00471.x

Trappe, H. (2013). Fathers Who Claim Parental Leave Benefits: Only a Matter of Economic Considerations? Zeitschrift für Soziologie, 42(1), 28-81. https://doi.org/10.1515/zfsoz-2013-0104

Waldfogel, J. (1998a). The family gap for young women in the United States and Britain: Can maternity leave make a difference? Journal of Labor Economics, 16(3), 505-545. https://doi.org/10.1086/209897

Waldfogel, J. (1998b). Understanding the "Family Gap" in Pay for Women with Children. The Journal of Economic Perspectives, 12(1), 137-156. https://doi.org/10.1257/jep.12.1.137 